\title{
The role of congenital malformations of the thoracic outlet in the development of the syndrome
}

\author{
M. Artico ${ }^{* *}$, M.T. Santarelli* * G. Stevanato ${ }^{2}$, R. Cirocchi , V. D'Andrea ${ }^{4}$, \\ A. Nicolai ${ }^{1}$, G. Cialone ${ }^{5}$, G. Monteleone ${ }^{6}$, I. Pindinello ${ }^{7 *}$, S. Taurone ${ }^{1 *}$ \\ ${ }^{1}$ Department of Sensory Organs, "Sapienza" University of Rome, Italy \\ ${ }^{2}$ Neurosurgery Unit, Dell'Angelo Hospital, Mestre, Venice, Italy \\ ${ }^{3}$ Department of Surgical Sciences, University of Perugia, Italy \\ ${ }^{4}$ Department of Surgical Sciences, Sapienza University of Rome, Italy \\ ${ }^{5}$ Unit of Radiology Regina Coeli, Rome, Italy \\ ${ }^{6}$ Department of Biomedicine and Preventive Medicine, Tor Vergata University of Rome, Italy \\ 'Department of Drug Chemistry and Technology, "Sapienza" University of Rome, Italy
}

[Received: 24 September 2020; Accepted: 2 December 2020; Early publication date: 30 December 2020]

Background: Thoracic outlet syndrome (TOS) represents a clinical condition caused by compression of the neurovascular structures that cross the thoracic outlet. TOS can be classified in: 1) neurogenic TOS (NTOS), 2) venous TOS (VTOS), 3) arterial TOS (ATOS). Many different causes can determine the syndrome: congenital malformations, traumas, and functional impairments.

Materials and methods: This manuscript reviews how the congenital malformations play an important role in adult age; however, TOS also affects patients of all ages. Results: Radiological imaging like $X$-ray (radiography), magnetic resonance and computed tomography can provide useful information to assess TOS causes and decide a potential surgery. $79 \%$ of the patients included in the first two stages of nerve, artery, vein (NAV) staging experienced excellent results with kinesiotherapy; whereas patients included in the third and fourth stage of NAV staging were subject to surgery.

Conclusions: The treatment of acute forms of TOS involves thrombolysis and anticoagulant therapy; surgery is appropriate for true NTOS, vascular TOS and in some cases when conservative treatment fails. (Folia Morphol 2022; 81, 1: 117-123)

Key words: brachial plexus, subclavian artery, subclavian vein, neuromuscular bundle, first rib, anterior and middle scalene muscle, congenital malformation, clinical grading, interscalene triangle, costoclavicular triangle

\section{INTRODUCTION}

Thoracic outlet syndrome (TOS) manifests with signs and symptoms that depend on the structure of the neurovascular bundle being compressed: the bra- chial plexus, the subclavian artery and the subclavian vein (Fig. 1) [4, 12]. The neurovascular dysfunction depends on three factors: 1) The space between the neck and the axilla is very limited; 2) Physiological

Address for correspondence: Dr. S. Taurone, Department of Sensory Organs, "Sapienza" University of Rome, V.le del Policlinico 155,00161 Rome, Italy, tel/fax: 0649918054, e-mail: t.samanta@yahoo.it

*These authors equally contributed.

This article is available in open access under Creative Common Attribution-Non-Commercial-No Derivatives 4.0 International (CC BY-NC-ND 4.0) license, allowing to download articles and share them with others as long as they credit the authors and the publisher, but without permission to change them in any way or use them commercially. 


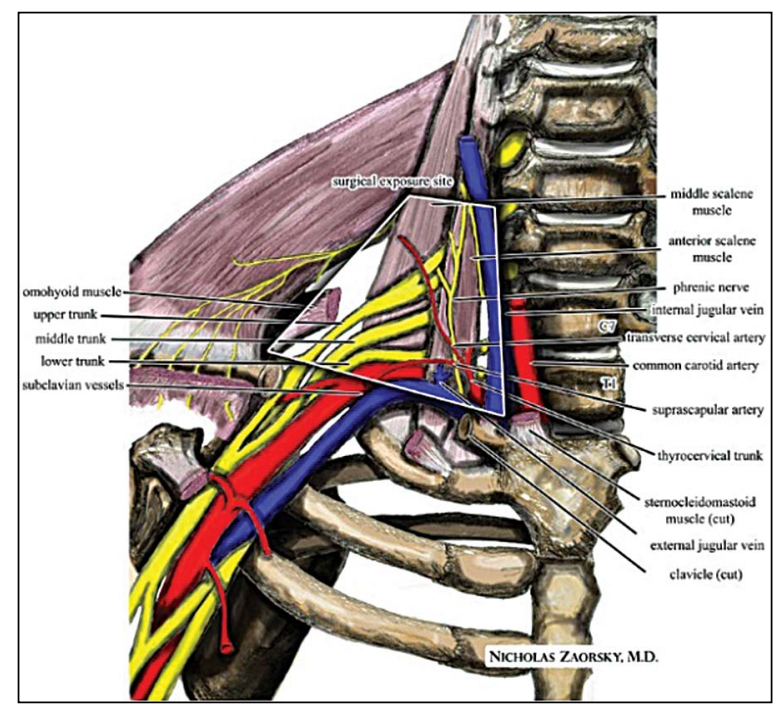

Figure 1. An illustration of the relevant neurovascular anatomy in anterior supraclavicular neurosurgical approach to the brachial plexus and subclavian vessels for thoracic outlet syndrome.

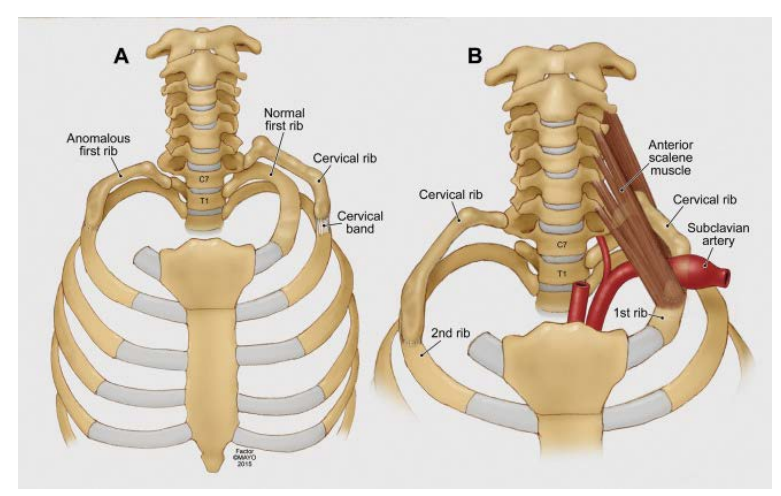

Figure 2. Arterial thoracic outlet syndrome; A. Right side: an anomalous first rib inserting into the mid portion of the right second rib, left side: a cervical rib originating from the transverse process of C7; B. Cervical ribs may insert on either the first rib or second rib.

conditions may cause intermittent compression to the neurovascular bundle; 3) Congenital malformations of bones and of muscles may trigger the symptoms. The classic subjects affected by TOS are young asthenic women with a thin neck and weak muscles. The structural anomalies involved in the TOS are: 1) Anomalous ribs, 2) Anomalous scalene tendon insertion, 3) Fibrous band insertion of the first rib, 4) Clavicular abnormalities (Fig. 2) [1, 6, 15].

\section{MATERIALS AND METHODS}

Thoracic outlet syndrome includes three different syndromes: 1) Neurogenic TOS (NTOS) with compression of the brachial plexus; 2) Venous TOS (VTOS) with compression of the subclavian vein; 3) Arterial TOS (ATOS) with compression of the subclavian artery $[10,11,14,18]$. The estimate of a suspected TOS may be assessed via medical history, medical examination and diagnostic tests that have, however, low sensitivity and low specificity but may support the diagnosis. To diagnose cervical ribs and anomalous first ribs one may use X-rays of the cervical spine and shoulder girdle and also computed tomography (CT), magnetic resonance (MR) and electromyography. Patients present symptoms of venous obstruction, arterial insufficiency, paraesthesia and pain $[2,8,14,16,17]$. The therapy is often conservative, including exercises and physical therapy. If it fails, it may be necessary to use surgical approaches such as supraclavicular exposure and the first rib resection. In this study we present a study of 181 clinical cases classified according to: 1) Type of malformation (cervical rib, anomalous first rib, scalenus medius insertion, scalenus minimus [Sibson's muscle] hypertrophy, Sibson's fascia band, fibrous band arising from incomplete cervical rib and elongated C7 transverse process, anomalous scalenus anticus insertion, anomalous vessels, hypertrophy of little pectoral); 2) Physical structure of the patient; 3) Gender. Any single case is classified through three parameters: nerve $(N)$, artery $(A)$, and vein $(V)$. There are four grades for each parameter according to clinical and instrumental severity (Table 1) [2]

\section{Neurogenic TOS}

The aetiopathogenesis of the neurogenic TOS includes various aspects: 1) Presence of thick fibrous band from the apex of sketch of cervical rib; 2) A work task that involves the prolonged abduction of the arms; 3) Physical characteristics; 4) Dominant $\operatorname{limb}[3,5,9]$.

\section{Clinical case 1}

Young woman, 19 years old (Figs. 3-5).

Task performed (job) at the time of the diagnosis: at the counter (Table 2).

Clinical malformation: fibrous band from sketch of accessory rib.

Clinical condition of NTOS: N3 (advanced neurological lesions), V1 (early venous lesions), A1 (early arterial lesions). The neurological disturbances depend on lesion of the fibres of the lower trunk of the brachial plexus; sensory symptoms appear in advance of motor signs and are often subject to pain and paraesthesia. The pain is diffuse in the su- 
Table 1. Pang grades; see Busetto et al. [2]

\begin{tabular}{|c|c|}
\hline Pang grades & NAV (nerve $[N]$, artery $[A]$, vein [V]) stages \\
\hline $\begin{array}{l}1=\text { pain and paraesthesia } \pm \text { intermittent postural } \\
\text { ischaemia } \pm \text { sympathetic instability }\end{array}$ & $\begin{array}{l}1^{\text {th }} \text { stage }=\text { N0-1 A0-1 V0-1 - Intermittent neurovascular compression } \\
\text { without anatomical damage }\end{array}$ \\
\hline $2=$ sensory deficits in ulnar distribution & $\begin{array}{l}2^{\text {th }} \text { stage }=\text { N2 A0-1 V0-1 - Anatomical damage: early and reversible } \\
\text { neurological lesions }\end{array}$ \\
\hline $3=$ intrinsic hand muscle weakness \pm atrophy & $\begin{array}{l}3^{\text {th }} \text { stage }=\mathrm{N} 3 \mathrm{~A} 2 \mathrm{~V} 2-\text { Anatomical damage: advanced neurological } \\
\text { lesions } \pm \text { early arterial lesions } \pm \text { advanced venous lesions }\end{array}$ \\
\hline $\begin{array}{l}4=\text { persistent ischaemic changes in hand (gangrene, skin necrosis) } \\
\text { resulting from emboli or subclavian thrombosis }\end{array}$ & $\begin{array}{l}4^{\text {th }} \text { stage }=\text { every N with } \mathrm{A} 3 \text { or } \mathrm{V} 3-\text { Anatomical damage: advanced } \\
\text { irreversible neuro-vascular lesions }\end{array}$ \\
\hline
\end{tabular}

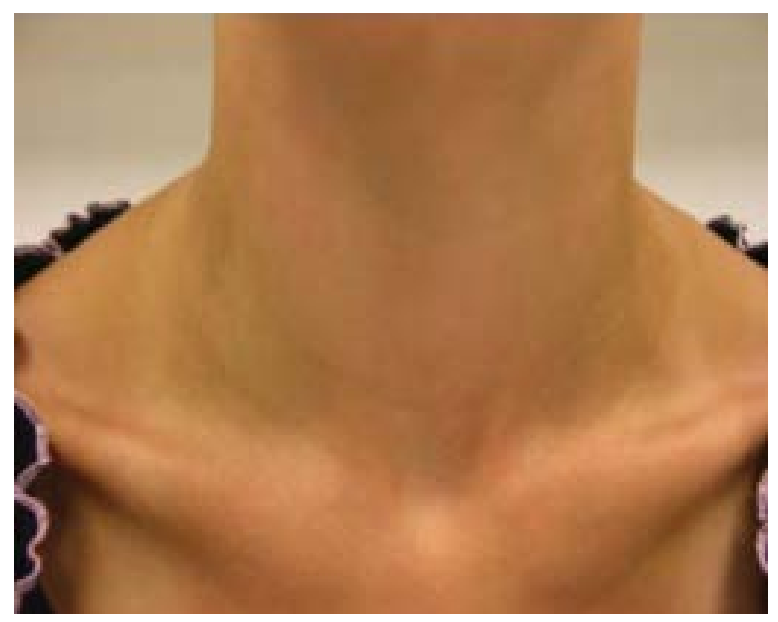

Figure 3. The image shows a young woman affected by bilateral accessory rib.

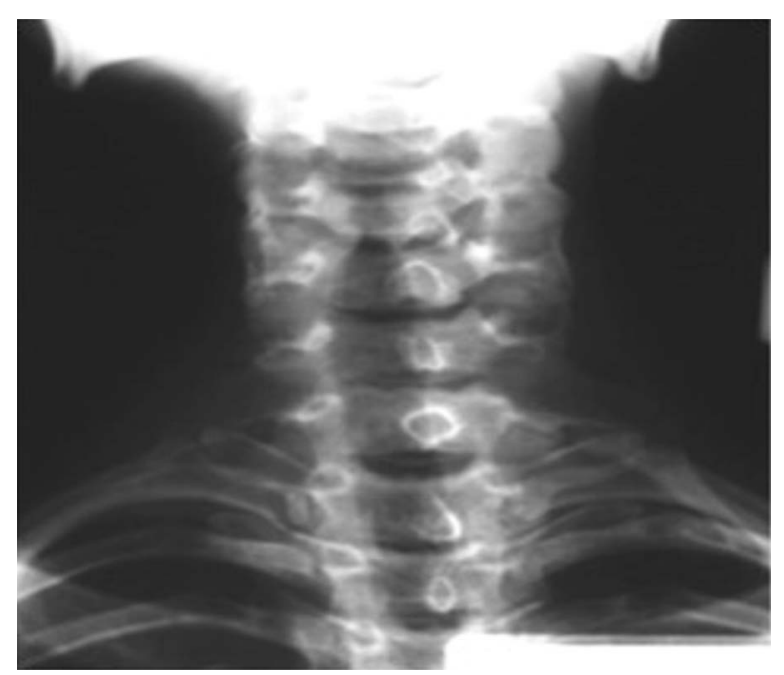

Figure 4. The X-ray of the cervical spine demonstrates the presence of right and left cervical rib.

praclavicular and shoulder region and widespread along the arm, and sometimes affects face and neck.

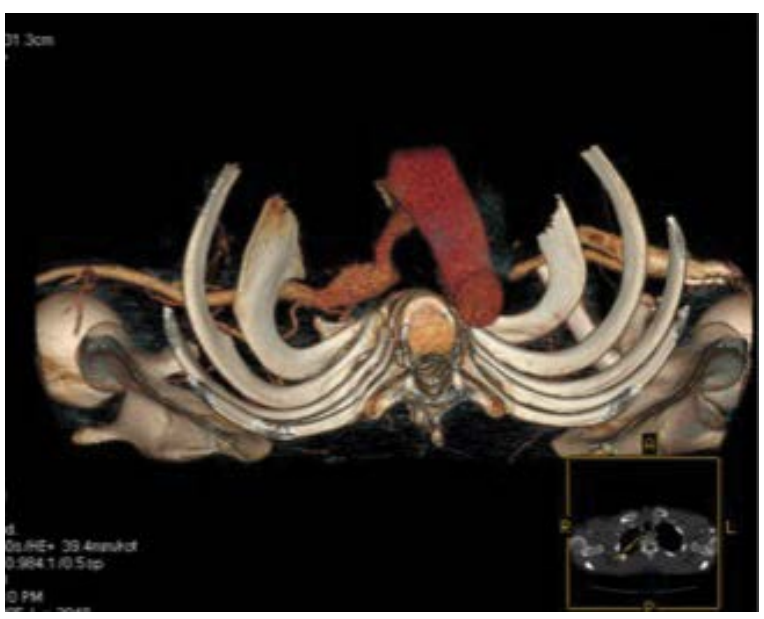

Figure 5. The contrast-enhanced computed tomography scan was reconstructed with volume-rendering algorithms and documents the compression by the accessory cervical rib on the neurovascular bundle.

The pain does not respect a C8-T1 dermatomal pattern, whereas the paraesthesia is usually localised to the C8-T1 ulnar side of the forearm. After some time the patient loses sensitivity in the ulnar fingers and show objective signs of sensory axonopathy in the C8-T1 dermatomes. The symptoms may be triggered by trauma to the shoulder and the pain gets worse after many hours of work. Motor disturbances: a testable weakness may indicate a motor axonopathy that manifests after some time from the beginning of sensory disturbance and means a worsening of the disease. The thenar muscles are affected first, followed by the hypothenar group (ulnar muscles). There is often consumption in the side part of thenar eminence giving a roughened appearance to the side outline of the hand (Fig. 6).

\section{Stress tests}

Experiments were performed in compliance with the Italian laws and guidelines concerning the in- 
Table 2. Homogeneous group of patients with the same malformation and a similar clinical stage (neurogenic thoracic outlet syndrome [TOS], positive electromyography, stage III)

\begin{tabular}{llcccc}
\hline Sex & \multicolumn{1}{c}{ Congenital malformation } & $\begin{array}{c}\text { Clinical picture } \\
\text { (neurogenic TOS, positivity } \\
\text { to electromyography) }\end{array}$ & $\begin{array}{c}\text { Age at } \\
\text { diagnosis }\end{array}$ & $\begin{array}{c}\text { Period between the } \\
\text { onset of symptoms } \\
\text { and the diagnosis }\end{array}$ & $\begin{array}{c}\text { Task carried out } \\
\text { at the diagnosis }\end{array}$ \\
\hline Female & Fibrous band from sketch of accessory rib & N3, V1, A1 & 19 & 36 months & At the counter \\
Female & Fibrous band from sketch of accessory rib & N3, V1, A1 & 24 & 43 months & Traffic warden \\
Female & Fibrous band from a prominent transversus & N3, V1, A1 & 41 & 32 months & Hair dresser \\
Male & Fibrous band from sketch of accessory rib & N3, V1, A1 & 38 & 83 months & Mechanical motorcycle \\
Female & Fibrous band from sketch of accessory rib & N3, V1, A3 & 22 & 17 months & Cashier - warehouse worker \\
\hline
\end{tabular}

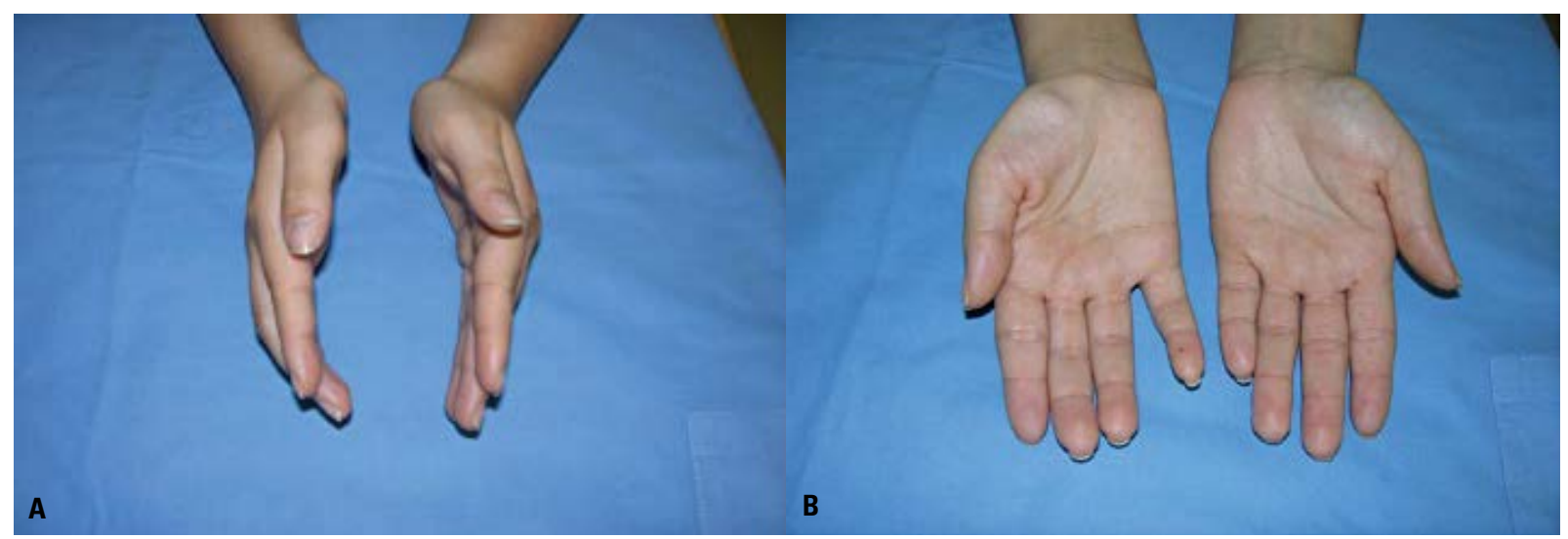

Figure 6. A, B. Thenar consumption in thoracic outlet syndrome. Note the severe thenar consumption especially with respect to the abductor pollicis brevis.

formed consent of patient (Dir.2001/20/CE). Stress tests are useful to diagnose the TOS because they increase the neurovascular compression at the thoracic outlet. There are many tests, each for a specific site of compression but the only reliable one is the 90 grades abduction external rotation test where the arm is abducted to a right angle and externally rotated while the head is turned to the opposite side. If the brachial plexus and the subclavian artery are compressed, the pain and paraesthesia are felt by the patient first in the ulnar area and then in the whole hand. If pain and tingling are extended without decreasing their intensity we can infer a purely neurogenic TOS [3]. The diagnosis is confirmed if by dropping the arm the discomfort is relieved and, also, if pain and tingling increase when opening and closing the fist for 3 minutes in the abduction external rotation position. The objective physical findings are very important for the diagnosis, e.g. weakness or atrophy of the hand, ulnar hypoesthesia, abnormalities of ribs and a positive electromyography. The radiological imaging cannot always lead to the diagnosis of TOS. Besides X-rays,
CT may also help to identify congenital malformation such as scalene muscle hypertrophy. $\mathrm{CT}$ angiography with the arm in hyperabduction may confirm the compression of neuromuscular bundle. Cervical spine MR images help to discover scalene muscle abnormalities. MR angiography with arms in different positions may confirm neurovascular compression. To discover deviations in the usual course of the nerves we can perform MR neurography by injecting a dye around the brachial plexus. Some patients affected by NTOS have anomalous nerve conduction velocities though this exam has low sensitivity and low specificity in the diagnosis of NTOS. Somatosensory-evoked potential may be useful in some cases of neurogenic TOS but have low specificity and can't locate abnormalities. The stimulation of the eighth cervical nerve is useful during a surgery but it is too invasive for outpatients. We can also use a combination of medial antebrachial cutaneous nerve conduction and C8 nerve root stimulation tests to do the diagnosis of NTOS $[2,3$, $5,9,19]$. Medial antebrachial cutaneous assessment is useful to reveal little alterations in the transmission 
of the lower trunk of the brachial plexus. Botulinum toxin injection into the anterior scalene muscle has been used for the diagnosis of NTOS and to reduce the symptoms (Fig. 7).

\section{Clinical staging and classification of TOS}

Thoracic outlet syndrome may be staged by its temporal sequence for severity and chronicity. In the first three stages there are weakness, pain and tingling in the whole hand (symptoms of intermittent ischae$\mathrm{mia}$ ). In the fourth stage there are persistent ischaemic changes in the hands like gangrene and skin necrosis from thromboembolism in the subclavian territory.

\section{Management of TOS}

Patients with NTOS should have a conservative treatment for three months and then a surgery can be taken into consideration. Conservative treatment includes soft physical therapy, muscle relaxants, anti-inflammatory drugs that determine an improvement of symptoms in many patients with a better function and return to work. Surgery is necessary when there are neurological dysfunctions and acute vascular insufficiency and functional impairments. Surgical procedures concern lysis of fibrotic band, scalenectomy and first rib excision.

\section{Arterial TOS}

ATOS is the least common type of TOS and is caused by a congenital malformation that determines a compression of subclavian artery. Possible malformations are: cervical or anomalous first rib, fibromuscular bands, scalene muscle [13].

\section{Clinical Case 2}

Young woman, 22 years old.

Tasks performed (job) at the time of the diagnosis: cashier (Table 2).

Clinical malformation: Fibrous band from sketch of accessory rib (Table 2)

Clinical condition of TOS: N3-V1-A3 (advanced neurological lesions, early venous lesions, advanced arterial lesions). The patient has persistent ischaemic changes in the hands (gangrene and skin necrosis) resulting from subclavian thrombosis (Figs. 8, 9). The arterial compression can determine aneurysm formation, growth of thrombi and embolization. Abnormalities of ribs are often involved in ATOS (74\% of cases). There are arterial damage, thrombus production and symptoms of claudication. Clavicle injury deformities

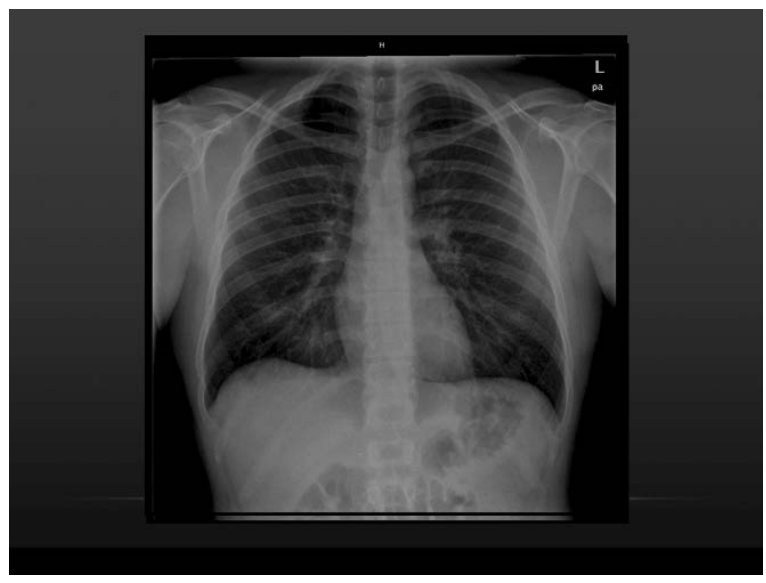

Figure 7. Antero-posterior cervical spine X-ray shows the presence of bilateral cervical accessory rib.

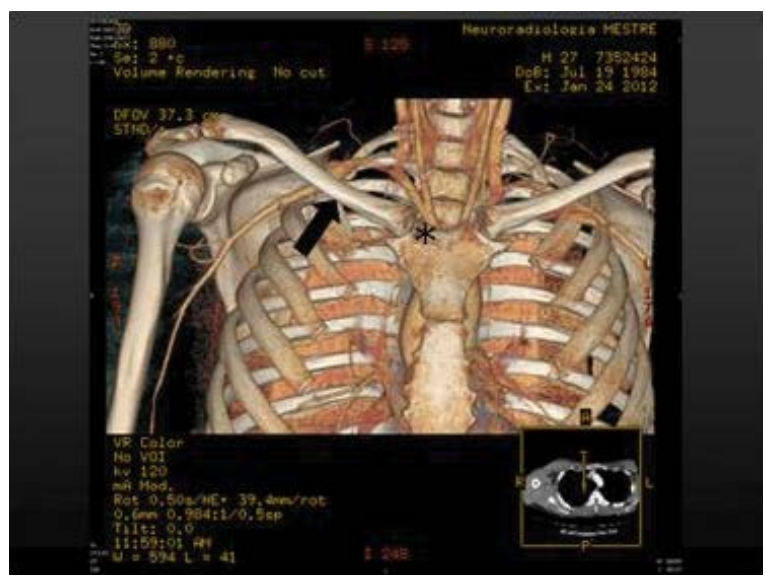

Figure 8. The contrast-enhanced computed tomography scan was reconstructed with volume-rendering algorithms. It documents thoracic outlet syndrome caused by the cervical rib compressing right subclavian artery $(\rightarrow)$. The right subclavian artery originates from the brachiocephalic trunk $\left({ }^{*}\right)$, then bends laterally passing between the scalene muscles. The image shows the backstage section of the right subclavian artery which contracts inferiorly with the first rib which is compressed by.

and compression may also determine ATOS by causing thrombosis and embolisation of the artery.

\section{Clinical presentation}

Arterial TOS is asymptomatic and symptoms like pain, tingling, cyanosis and changes of colour of the hands (until gangrene) may appear when embolization occurs. There is absence of radial pulse and signs of ischaemia of the distal phalanges. The objective examination of the patient can reveal a bony prominence and is possible to palpate pulsation of the supraclavicular artery 


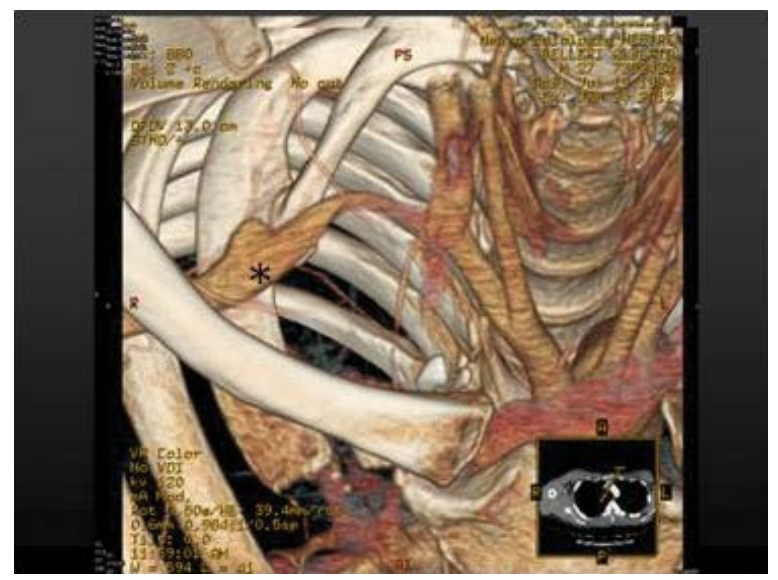

Figure 9. The contrast-enhanced computed tomography (CT) scan was reconstructed with volume-rendering algorithms. It documents the costo-clavicular triangle delimited anteriorly by the middle third of the clavicle, posteromedially by the first rib and posterolaterally by the upper profile of the scapula. The CT shows the irregularity of the profile of the subclavian artery with an evident dilation $(*)$ upstream of its compression at the level of the costo-clavicular triangle.

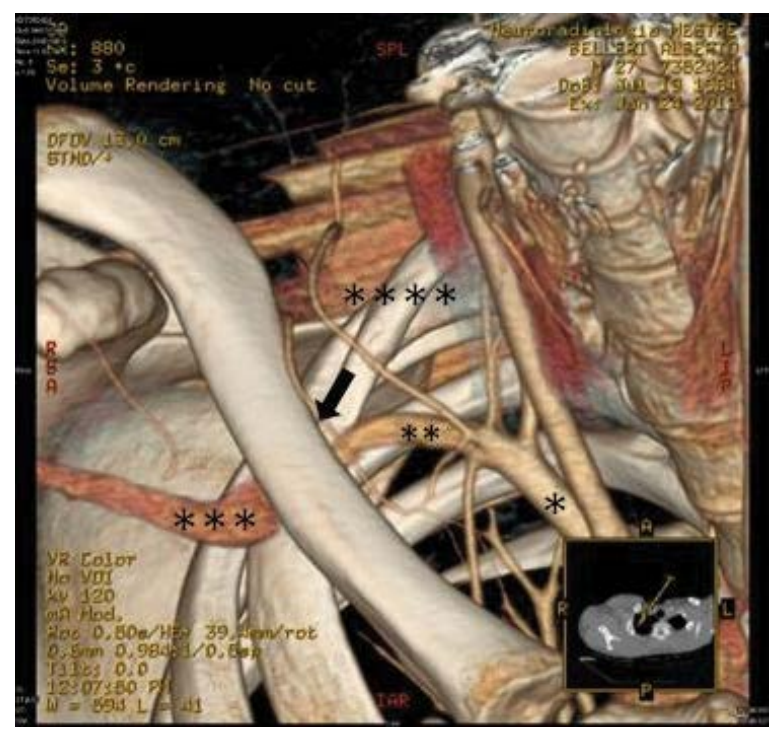

Figure 10. The contrast-enhanced computed tomography scan documents the stenotic effect of the subclavian artery $(\rightarrow)$ during the Adson test. In particular when the patient, while seated, rotates his head and elevates his chin to the side in which is suspected the syndrome, the compression on the subclavian artery by the cervical rib is increased determining a stenotic effect; *brachiocephalic trunk; ${ }^{* *}$ pre-stenosis subclavian artery; ${ }^{* * *}$ post-stenosis subclavian artery; ${ }^{* * *}$ cervical rib.

\section{Diagnosis}

We can make the diagnosis by confirming a compromised circulation of the artery and identifying an anatomical factor responsible for arterial obstruction. Experiments were performed in compliance with the

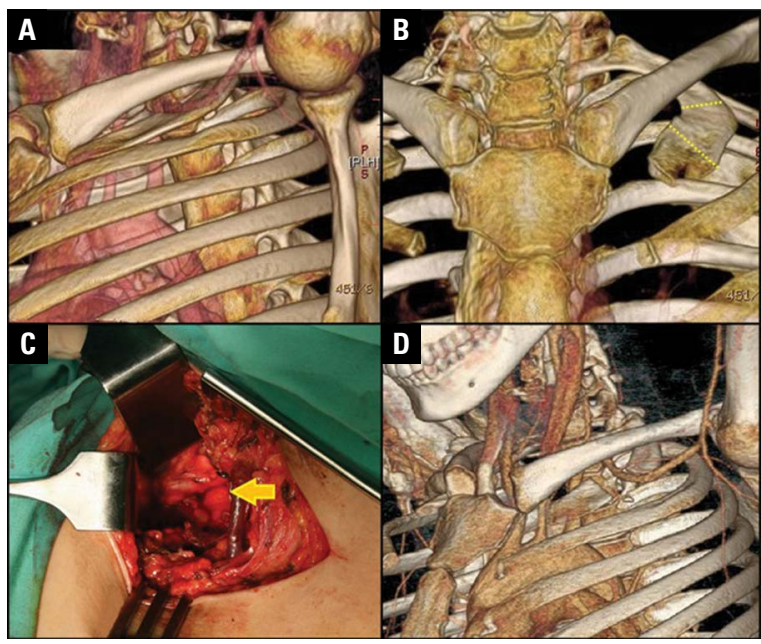

Figure 11. A. Preoperative computed tomography (CT) shows the first rib compressing the subclavian artery; B. Preoperative planning of the excision; C. Transaxillary first rib resection. at the level of the scalene tubercle (arrow) and myotomy; D. Postoperative CT shows partial resection of the first rib and the decompressed subclavian artery.

Italian laws and guidelines concerning the informed consent of patient (Dir. 2001/20/CE). A provocative test may suggest the diagnosis of arterial insufficiency (Fig. 10): 1) Adson test: if the patient, while seated, rotates his head and elevates his chin to the side where the syndrome appears localised causes his pulse to decreases or disappear, then the test is positive for vascular compression by anterior scalenus muscle or cervical rib (Fig. 8); 2) The overhand exercise test: the patient raises both arms overhead and quickly extends and flexes the fingers; if he fills pain, sense of weight, tingling and pallor appears in 20 seconds then the test is considered positive. Instrumental examinations useful for diagnosis are standard arteriography, MR or CT angiography, Doppler ultrasonography, which can be associated to postural manoeuvres to reveal the arterial impairment. The arteriography performed with the patient seated has more sensitivity than in supine position, in particular if he changes the position of the arms $[7,9,17]$.

\section{Management}

It is necessary to identify the site of arterial compression and the surgery of resection of cervical or anomalous first rib and of scalene muscle release and arterial reconstruction (Fig. 11). Not all patients treated with cervical or anomalous first rib resection are able to return to their level of physical activity because there are often delays in treating chronic-pain syndrome [3]. 


\section{RESULTS}

Seventy-nine per cent of patients were included in the first two stages of nerve, artery, vein (NAV) staging (148 cases) and provided with physio-kinesiotherapy experienced good/excellent results, whilst the remaining $21 \%$ were transferred to the third stage. 33 patients that were included in the third and fourth stage underwent surgery with excellent results on vascular and sensory neuropathic disorders. However, the operations did not completely restore the hand fine motility due to the severe hypotrophy of the affected muscles. The retrospective analysis of our study showed that the tendon bands stretched between the sketch of the accessory rib and the first rib, associated with other factors (dominant limb, physical characteristics, prolonged limb abduction) are the most common cause of neurogenic TOS (N3 of the NAV staging). Indeed these malformations - which compress the lower primary trunk from below - can develop in a subtle way severe deficits in the hand motility, without causing particular pain or sensory disturbances.

\section{DISCUSSION}

Cervical rib and anomalous first rib are predisposing factors for the development of TOS, but in most patients more than an osseous abnormality must be present to determine symptoms. Often a neck trauma, either work-related or not, happens before the appearance of symptoms. The presence of a cervical rib or anomalous first rib, by itself, does not imply that surgery is necessary even with symptoms of disability and non-responsiveness to conservative therapy $[1,11,15]$. The diagnosis of neurogenic TOS should be made, above all, on the basis of clinical findings whether with or without any osseous abnormality. However, anomalous first ribs can determine arterial stenosis that can remain asymptomatic until thrombosis or embolisation occurs. Therefore, if neurogenic symptoms do not lead to the necessity of surgery, the patient must be evaluated and monitored with duplex scanning for stenosis or aneurysm formation. Although there aren't clinical trials comparing operative and non-operative therapies for TOS, common surgical interventions include excision of first rib, scalenectomy and lysis of fibrotic band (Fig. 9) $[7,13]$. Excision of the cervical rib may be performed with or without the first rib, but often - if the first rib is not excised - there is a higher operation failure rate. The explanation for such better results (i.e. when the first rib and cervical rib are both removed) is not obvious. The treatment of acute forms involves thrombolysis and anticoagulant therapy followed by the decompression of the thoracic outlet. Surgery is appropriate for true neurogenic TOS, vascular TOS and patients for whom conservative therapy fails. Operative intervention often gives good results [3].

\section{Conflict of interest: None declared}

\section{REFERENCES}

1. Bianchi $E$, Mancini $P$, De Vito $S$, et al. Congenital asymptomatic diaphragmatic hernias in adults: a case series. J Med Case Rep. 2013; 7: 125, doi: 10.1186/1752-1947-7-125, indexed in Pubmed: 23668793.

2. Busetto A, Fontana $P$, Zaccaria $A$, et al. Thoracic outlet syndrome: clinical staging. Italian Surg. 2004; 56(N1): 55-62.

3. Cavallotti C, Artico M, Cavallotti D. Occurrence of adrenergic nerve fibers and of noradrenaline in thymus gland of juvenile and aged rats. Immunol Lett. 1999; 70(1): 53-62, doi: 10.1016/ s0165-2478(99)00127-3.

4. Dachling P. Diagnosis and surgical management of thoracic outlet syndrome. Techn Neurosurg. 2000; 6(1): 27-49, doi: 10.1097/00127927-200006010-00005.

5. Ferrante MA, Ferrante ND. The thoracic outlet syndromes: Part 1. Overview of the thoracic outlet syndromes and review of true neurogenic thoracic outlet syndrome. Muscle Nerve. 2017; 55(6): 782-793, doi: 10.1002/mus.25536, indexed in Pubmed: 28006844.

6. Huang JH, Zager EL. Thoracic outlet syndrome. Neurosurgery. 2004; 55(4): 897-902.

7. Hussain MA, Aljabri B, Al-Omran M. Vascular thoracic outlet syndrome. Semin Thorac Cardiovasc Surg. 2016; 28(1): 151-157, doi: 10.1053/j.semtcvs.2015.10.008, indexed in Pubmed: 27568153.

8. Illig KA, Rodriguez-Zoppi E, Illig KA, et al. The incidence of thoracic outlet syndrome. Ann Vasc Surg. 2021; 70(1): 263-272, doi: 10.1016/j.avsg.2020.07.029, indexed in Pubmed: 32771464

9. Khun E, Lbus VGF, Bible E. Thoracic outlet syndrome. J Am Acad Orthop Surg. 2015; 23(4): 222-232.

10. Likes $\mathrm{K}$, Dapash $\mathrm{T}$, Rochlin $\mathrm{DH}$, et al. Remaining or residual first ribs are the cause of recurrent thoracic outlet syndrome. Ann Vasc Surg. 2014; 28(4): 939-945, doi: 10.1016/j.avsg.2013.12.010, indexed in Pubmed: 24462539.

11. Likes K, Rochlin DH, Call D, et al. Coexistence of arterial compression in patients with neurogenic thoracic outlet syndrome. JAMA Surg. 2014; 149(12): 1240-1243, doi: 10.1001/jamasurg.2014.280, indexed in Pubmed: 25322469.

12. Nichols A. Diagnosis and management of thoracic outlet syndrome. Curr Sports Med Rep. 2009; 8(5): 240-249, doi: 10.1249/ jsr.0b013e3181b8556d.

13. Raptis CA, Sridhar S, Thompson RW, et al. Imaging of the patient with thoracic outlet syndrome. Radiographics. 2016; 36(4): 984 -1000, doi: 10.1148/rg.2016150221, indexed in Pubmed: 27257767.

14. Rochlin DH, Orlando MS, Likes KC, et al. Bilateral first rib resection and scalenectomy is effective for treatment of thoracic outlet syndrome. J Vasc Surg. 2014; 60(1): 185-190, doi: 10.1016/j. jvs.2014.01.034, indexed in Pubmed: 24709438.

15. Sanders RJ, Hammond SL. Management of cervical ribs and anomalous first ribs causing neurogenic thoracic outlet syndrome. J Vasc Surg. 2002; 36(1): 51-56, doi: 10.1067/mva.2002.123750, indexed in Pubmed: 12096257.

16. Seifert $S$, Sebesta $P$, Klenske $M$, et al. [Thoracic Outlet Syndrome] Zentralbl Chir. 2017; 142(1): 104-112, doi: 10.1055/s-0042121611, indexed in Pubmed: 28303559.

17. Spartalis $E$, Spartalis M, Tsilimigras $D$, et al. Extensive or partial first rib resection for thoracic outlet syndrome? The contribution of three-dimensional imaging to the preoperative planning and the postoperative evaluation. Clin Case Rep. 2018; 6(8): 1631-1632, doi: $10.1002 / \mathrm{ccr} 3.1617$

18. Taviani $M$, Prandi $M$, lurilli $L$, et al. Ourexperience with thoracic outlet syndrome. G Chir. 1996; 17(6-7): 329-331.

19. Vemuri $C, M c L a u g h l i n ~ L N$, Abuirqeba AA, et al. Clinical presentation and management of arterial thoracic outlet syndrome. J Vasc Surg. 2017; 65(5): 1429-1439, doi: 10.1016/j.jvs.2016.11.039, indexed in Pubmed: 28189360. 